\title{
An Interpretative Phenomenological Analysis of the Emotional Experience of the 1947 Partition Survivors
}

\author{
Ananya Kalra ${ }^{1}$ and Eva Zysk ${ }^{1}$ \\ ${ }^{1}$ University of British Columbia, Vancouver, BC, Canada \\ DOI: https://doi.org/10.47611/jsr.v10i1.1138
}

\begin{abstract}
This paper examines the emotional experience of the survivors of the 1947 India-Pakistan Partition by conducting an interpretative phenomenological analysis of their trauma narratives which were procured through the 1947 Partition Archive, an organization dedicated to the preservation of the stories of victims of the separation of the two countries. The three participants were between the ages of 514 years old when they were displaced, and all of them witnessed the rampant violence that characterizes the Partition. They recall the events while maintaining a distance from the distressing memories by altering the perspective of their narratives and adopting laughter as a relieving mechanism. Their cultural identity was comprised by forced migration which they express through a deeply rooted desire to return to their homes. The research offers insight into the psychological and emotional experiences of the participants as they remember the events of the Partition. There needs to be further exploration of Partition narratives across diverse demographics, such as South Indian and Muslim survivors.
\end{abstract}

\section{Introduction}

The partition of India and Pakistan in 1947 became the largest known mass migration in history (Independence and Partition, 1947 | National Army Museum). Next-door neighbours turned against each other, instigated by religiondriven animosity; Hindus and Sikhs attacked their Muslim counterparts on the Indian side of the newly formed border, and vice versa on the Pakistani side. The division of the country resulted in explosive violence as a result of the communal animosity that had been brewing in prePartition India (Talbot, 2009). Yusin (2009) estimates 1 million casualties, and approximately 12 million people participating in the exodus from either side of the border. Meanwhile, Bhasin and Menon (1998) claim that approximately 8-10 million refugees entered Bengal, and nearly the same number of Muslim refugees fled from new India out of which approximately half to a million died before they reached their destination. This event left affected people without homes, money, and in most cases, resulted in the death of family and friends. The official narrative surrounding the Partition is clouded by estimates and inconsistent information.

Historians like Butalia $(2000)$ and Talbot $(2009 ; 2019)$ attempt to understand and explain the nature of the violence that took place; in the process they offer a glimpse into the suffering of survivors as they lived through the Partition. However, few studies in the field of psychology have attempted to approach the issue of mental and emotional wellbeing of survivors of traumatic events in South Asia (Mushtaq, Shah \& Mushtaq, 2016; Bhadra, 2012), especially in the context of the Partition (Nandrajog, 2018) which means that the psychological impacts of one of the turning points in the history of India and Pakistan have gone unexplored.

Nandrajog (2018) offers one of the few psychological studies on the impact of the events on its survivors by conducting an analysis of the fictional literature written in the aftermath of the Partition. Key themes observed in the literature as psychological consequences of the Partition are: (1) Loss of communal identity and sense of self, (2) Coping and the endurance of the human spirit, (3) Escaping into relics of the lost life, (4) Rebuilding identity on a religious foundation, (5) Alienation on either side of the border, (6) Looking to the future generations for closure. However, the study relied exclusively on works by older Indian authors such as Manto who survived the Partition. 
This medium allows little space for the exploration of the female point of view as the literary field consisted mostly of men, as it does for understanding the experiences of children. Children are a highly vulnerable group who undoubtedly faced a different reality than their older counterparts in trying to make sense of the events that took place during time of widespread conflict and displacement. Childhood exposure to trauma influences short-term developmental factors and elicits symptoms such as clinging behavior, disruptive behavior in classrooms, hypersensitivity and confusion surrounding religion, hypervigilance, nyctophobia, as well as traumatic mutism. Additionally, most of the children caught in communal violence were also forbidden by their parents to talk about the events they witnessed, and in many cases lost part of their support and religious system (Bhadra, 2012). Externalization includes behavioral changes, lower academic performance, avoidance of people, places and thoughts, as well as a loss of appetite are some other symptoms seen in Kashmiri children (Mushtaq, Shah, Mushtaq, 2016). These effects may be detrimental to the future of these children, however, little is known about the influences of these factors in further development of children into adults in a conservative society like India's, where there is limited awareness of the importance and implications of mental wellbeing(Shah et al., 2020). As a close approximation for Partition research that study the impact of traumatic national events in hindsight would be Holocaust studies where the the subjective transformation of events within the psyche of the survivor is perhaps the best studied from childhood to adulthood,t. Talbot (2019) draws a parallel between the two as statesanctioned genocide that was ethnically motivated.

Oral history provides an intimate understanding of the participants' lived experiences that official documents fail to provide. It is a medium through which to preserve and understand the past. An interpretative analysis of participants' experiences illuminates the different sentiments of the participants interviewed by a nonprofit organization. The intention of the study is to focus on the individual experiences of each interviewee. Understanding the emergent themes may provide an insight into the cultural differences between trauma narratives. Whether what one includes and excludes from a narrative is culturally determined can also lead to the formation of doubly efficient modes of understanding culturally diverse narrative.

The interviews conducted by the '1947 Partition Archive' were analyzed using the Interpretative Phenomenological Analysis method. Being of a "double hermeneutic" (Smith \& Osborn, 2003, 53) nature, the method encourages the researcher to step into the participant's world and empathize, all the while remaining inquisitive of their experience. The consideration of one's speech's nuances, like their laugh or hesitation, allows a detailed analysis of their emotional state regarding an event.

This paper focuses on the emotional experience of Partition survivors by analysing the themes that emerge from their verbal narratives. The purpose of this study is simply to learn about the experiences of some of the people that witnessed the effects of the Partition.

\section{Methods}

This is a qualitative analysis of Partition survivor interviews conducted by and video recorded by the 1947 Partition Archive. Interpretative Phenomenological Analysis (IPA) has been used to analyse the data to harvest a comprehensive understanding of the lived experiences of the survivors. IPA facilitates an in-depth exploration of the emotional state of the survivors while the events of the Partition unfolded around them.

\section{Data}

Interviews used for the project are publicly available on the Stanford Digital Repository courtesy of the 1947 Partition Archive. They were all conducted approximately 70years after the events of the Partition first took place. The video interviews were gathered by the organization's volunteer interviewers or "Citizen Historians" who are trained in proper interviewing techniques and provided with comprehensive questionnaires by the organization through online webinars. The researcher attended the webinar to become familiar with the interview practices adopted by the organization; they suggest the interviewers employ semistructured interview techniques to allow the participant the space 
to properly convey their history during the interview. The data was first translated by the lead author from Hindi to English for two of the participants then transcribed, while the third was a direct transcription from English.

\section{Participants}

The interviews analysed were purposively sampled based on (1) the ethnicity of the participants, and (2) open access to the interview. Ethnicity played a key role during the events of the Partition as the main cause cited for the division of the country (Butalia, 1998). In an effort to regard those involved with equal empathy and understanding which is an important aspect of IPA (Smith and Osborn, 2003, p. 54), the intention was to include participants that identified as Hindu, Muslim, and Sikh. However, due to access and language constraints, the pool of participants was narrowed down in such a way that was more representative of the Hindu and Sikh population. The participants are referred to as Babita (F), Neerja (F) and Ajit (M) to protect their identities. At the time of the interview, the participants fell between the ages of approximately 75-84. All three participants are migrants from present-day Pakistan who had witnessed some form of violence when they were between the ages of 5-14 years old. Ajit experienced things such as a direct threat to his life and that of his family when they were stranded in a stationary train for over a week; this included starvation, dehydration, and the threat of violence at the hands of Muslim attackers. Neerja suffered witnessing her mother's severe distress at having left everything behind in Pakistan and was forced to grow up faster to take care of her. In Babita's case, her family was thrust into poverty following their escape to India from Pakistan. The long-term outcomes for each of the participants differ, however the fact remains that they all experienced a great immediate and long term decrease in their quality of life directly as a result of the Partition.

Table 1. Estimated ages of the participants at the time of the Partition and interview

\begin{tabular}{|c|c|c|c|}
\hline Participant & Gender & $\begin{array}{c}\text { Age at time of } \\
\text { Partition (in years) }\end{array}$ & $\begin{array}{c}\text { Age at time of } \\
\text { Interview (in years) }\end{array}$ \\
\hline Ajit & Male & 11 & 81 \\
\hline Babita & Female & 6 & 75 \\
\hline Neerja & Female & 14 & 84 \\
\hline
\end{tabular}

\section{Data Analysis}

The analysis was informed by the recommendations of Smith and Osborn (2003). The interviews were translated and transcribed by the researcher who is an Indian native and fluent in Hindi and English. The translated transcript was revised twice to ensure clarity and adherence to the participant's narrative. The transcript was first pre-coded following which key phrases and words were annotated based on frequency. This process was repeated to narrow down the data to recurring patterns. Themes were then identified and compared to the transcripts to ensure richness and relevance, as well as to capture any potential lapses in understanding as the researcher draws onto her own faculties of understanding to interpret the participants' experiences (Smith and Osborn, 2003).

\section{Results and discussion}

Upon analysing the interviews two major themes relevant to the emotional experiences of Partition survivors emerged: (1) living with the past and (2) sense of belongingness. Some of other themes were omitted from analysis due to sparsity of data or irrelevance to the research topic, such as: lack of clarity and misinformation about the events of the 
Partition; disruption of life ; tolerance towards Muslims ; feminine vulnerability ; posttraumatic growth ; and discussions surrounding the Partition with loved ones. Themes analysed have outlined in Table $2 \& 3$.

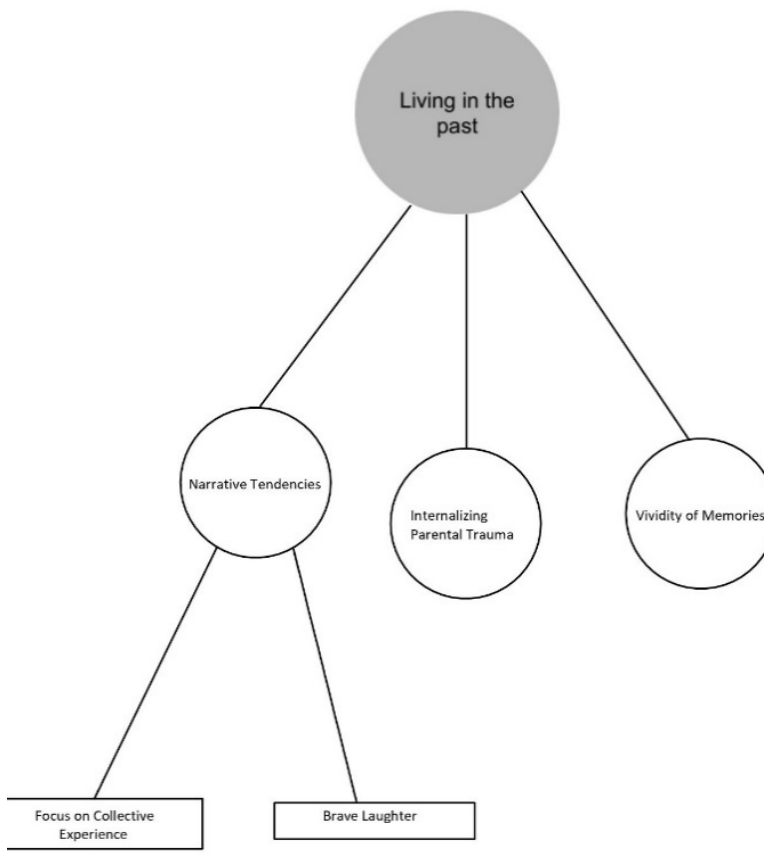

Living with the past

All the participants were witnesses to the depravity of genocidal violence. The experience of such cultural trauma alters one's worldview, especially in adolescents and pre-teens as they develop (Konvisser, 2013; Werner, 2012). Additionally, it disrupts one's identity and selfconcept; the process of understanding the events and themselves in relation to it (Marin \& Shkreli, 2019) means that their past trauma contributes to the formation of their present self. Stressful life events such as exposure to communal strife at an early age, impact behaviors and cognitions (Matsumoto, 2009; Filkuková et al.,2016; Bhadra, 2012) here evidenced in their narrative tendencies, vividity of memories, and in one case, their mimicking of parental trauma.

\section{Narrative tendencies}

Focus on collective experience: The experiencing of traumatic events factors into the narrative surrounding stressful life events (Filkuková et al., 2016; FernándezLansac \& Crespo, 2017; Talarico \& Rubin, 2007). Ajit's account of the events of the Partition produced a notable trend where he removes himself from his recollection of the events that took place in 1947, instead focusing on the collective's experience of what took place. He does this in multiple parts of his narrative, for example:

A: Yeah. And we had no food, nothing to drink, and no utensils. My father had given us a wooden box, this big. It had some flour, some matches, and things like that inside it. And after breaking the box, we made rotis morning and evenings on the platform, by setting up bricks. I don't know where it went but there was this poor tava (castiron pan used to make flatbreads) as well. There was nothing else with it, just the rotis and those too you would get tiny ones and the same thing in the evening. We were there 13 daysmany people died. Where the platform was, on the other side was a city and a very dirty pond as well, which had cow and buffalo bones in it. People were dying and they would just get thrown in there.

This excerpt relates to when his family and he were in a train stranded in Kasoor, a Pakistani station where they were surrounded by Muslim attackers. They were without easy access to food and water for thirteen days, an undoubtedly 
traumatic experience. Ajit's approach to the topic makes it so his individual presence as the event took place is diminished, that is he avoids disclosing his personal and inner experience to the interviewer until he is asked directly about his emotional state at the time, to which he responds by claiming to be too unaware to have felt anything. He chooses to draw focus to the collective "We" in these scenarios as opposed to the "I"; his only reference to "I" in the excerpt refers to him postPartition. The research on this behavior is sparse, a close approximation being the dialogue type adopted by individuals expressing posttraumatic stress symptoms (PTSS), where both Low PTSS and High PTSS preferred to discuss others in their narratives, over their own verbalizations or that of the perpetrator (Filkuková et al., 2016). On the contrary, this may also be a result of the nature of the trauma; the Partition is a cultural trauma, that is, a group "share(s)" the trauma (Taylor \& Usborne, 2010, p. 106) which may promote the usage of collective pronouns over personal.

However, this may also be an effort to preserve a familiar self or self sameness (Marin \& Shkreli, 2019) which suggests that the removal of the self from stressful recollection could be a tool to mitigate the negative affect associated with the memory. On the other hand, Filkulová, et al. (2016) suggests that distancing of oneself may be reflective of recovery from the unpleasant emotions bound to the memories of the event. The lack of focus on self may be because of emotional distance due to exposure to trauma while young, as indicated by the lack of emotional word usage in their narrative (Wardecker et al., 2017). It may also be related to the human tendency to want to maintain a positive self concept which may be achieved by reorganization of trauma narratives, as well as by trying to reinterpret the events, and perhaps the perspective through which one views the past (Grysman, 2012). Since traumatic events shift an individual's perception of self, the tendency to create distance between the pastself and the present self may be an effort to protect the continuity and understanding of one's identity.

Brave laughter: A noteworthy behaviour that was present in all three participants' interviews was laughter as they disclosed emotionally charged memories. This seemed misplaced, and thus could likely be used to diffuse tension. For example, Ajit makes a joke about how his family was victimized twofold when they lost the last of their belongings because of train mismanagement and widespread thievery:

A: (Their belongings are) still coming [laughing]! Those wagons are still coming to this date! I mean, we became victims again [laughing]! First, we got robbed there, then again we got robbed in Jaillum!

Another example of this in response to a chronic stressor is Babita's account of her family's descent into poverty after they were displaced to Rajasthan, a desert state in India after the Partition:

B: I never felt deprived or poor. Um, but you know, how children compare, Oh, what did you get? What did you get? So, we just wouldn't show them what we got (laughs).

According to Jefferson (1984, as cited in Ladegaard, 2013) "brave laughter" (p. 391) is a humourless laugh adopted during painful disclosure. The loss of property, family, childhood, and so on is presented to the interviewer by the participants with humour most likely to lend the moment some lightheartedness, and make the emotional disclosure more bearable for the survivors. For example, similar behaviour has been identified in older widowed Japanese women while they recounted the deaths of their husbands and used humor to both laugh themselves and to make the listener laugh (Matsumoto, 2009). Laughter may help mitigate unpleasant emotions associated with the memories by distancing the speaker from the past. This is evident in the case of a participant, Neerja who mourns for her mother's mental condition after the Partition; the laughter may allow her to take a step back from the torrent of emotion that accompanies such recollections. This might also be a social consideration that removes the weight on the individual's misfortunes off of the shoulders of the listener (Ladegaard, 2013) because not only does the participant laugh but the laugh is mirrored by the listener, in this case, the interviewer. Though Matsumoto argues that humor is meant to ease tensions surrounding taboo topics that generate sadness and discomfort (2009), they also assert the need for "a 
commonality of life experience" (2009, p. 947) in order to successfully incorporate humor into painful self-disclosure. The shared laughter between the interviewer and the participants suggests that shared cultural knowledge and social politeness may take precedence over shared life experiences in this regard.

\section{Vividity of memories}

Across the interviews, the participants gave incredibly detailed accounts of the events as they remembered them, similar to the flashbulb memory phenomena as posited by Neisser \& Harsch (1992) which is characterized by the great amount of detail associated with emotional memories. From details of the various hiding places on their journey to the landmarks near a temporary home, the survivors recounted surprisingly small details during the interview. An example of such detailed retelling can be seen in Babita's account:

B: Then we drove a little further and the other images were, on the same canal road, buses had toppled over. People's grain, their bread, and bodies all over. And then, if you looked into the canal [sharp intake of breath], there were heads, and bloated bodies, floating. So, my mother said, Don't look, don't look. And she would put her scarf over, her chunni over our eyes. But the images, I would say that I clearly still remember. And so, we went to the village. Later, I understood this is what they told them. We didn't sleep in that village, we went to the next village, and it was in summer, August, right? Um, we were sleeping on top of the roof, um, with whoever-everyone in the Punjab knew each other, the big families did. So, they knew, these are Dhillon's from Lahore, they're Sardars. So, they knew that we were sleeping upstairs and we-we looked, and that too I remember, the flames from the village next door. The village where they had said, don't stay.

One of the criticisms of the flashbulb memory theory is the inaccuracy of people's accounts (Neisser \& Harsch, 1992); however, there is some evidence that levels of perceived distress associated with an event is positively correlated to accuracy of recollection even more than a year after the event first took place (Er, 2003). Two of the three participants had shared their experiences with other people; Babita implies that her family talked to her about the events that had taken place in their journey to India while she was still young, while Neerja seems to have only discussed her story with her husband. Rehearsal may account for the indepth recollection of memories; however, Ajit also provided vivid accounts despite claiming to never have talked with anyone about them. These recollections may be categorized as "flashbulb memories", i.e. memories created upon learning of and/or experiencing an emotionally charged event (Brown \& Kulik, 1997). These memories are rated as being more vivid over a long period of time than everyday recollections (Talarico \& Rubin, 2007) because they act as "landmarks in autobiographical memory" (FernandezLansac \& Crespo, 2017, p. 80). The detail with which they recount their journey might suggest that certain events are remembered more clearly than others, perhaps because of the emotional value they hold. This may simply be a primal response to perceived danger to one's life or the result of repeatedly ruminating over stressful events. Another observation of interest is Babita's usage of the word "image" to describe the memory that suggests there is a photographic quality to the memory; this follows the logic of the 'flashbulb' lighting at the recollection of a specific memory.

\section{Internalizing parental trauma}

Neerja left her village by bus to escape the coming violence, while her mother and other family members stayed behind and travelled as a kafila or a group that travelled by foot. When asked about the circumstances of her journey she claims she "got out easily" but it was the family members following her that "had a very tough time".

Neerja recalls her mother's deteriorating mental condition after they reunited with each other while fleeing Rawalpindi at the peak of the Partition's violence:

$\mathbf{N}$ : What happened to her was, "I've gone and gotten everything stolen." Went crazy (choked laugh). 
Her mother's trauma stemmed from the journey she had to make for over half a month and witnessing the loss of all her possessions. Neerja herself was privy only to details of the journey passed on to her by family members and believed that she would return home soon. She implies that her mother was ailed by the trauma of having lost her home and livelihood, a phenomenon observed in women fleeing active conflict zones, as well (Seguin et al., 2015). Throughout her interview Neerja goes on to mimic the sentiment of having had "everything stolen" from her, as opposed to having lost everything or "left everything behind" as in the case of Babita. This sense of being stolen from may be reflected in an intolerant attitude towards Muslims characterized by a sense of having been wronged by them, distrust, and so on (Isserman, 2009):

$\mathrm{N}$ : Theythey ate away all our things, why would they help us?

I: Okay, they looted all your stuff?

$\mathrm{N}$ : They robbed and looted us of everything. Even our house, the cinema, what else?

Neerja clearly deeply empathizes with her mother as she became her primary caretaker through her mother's illness; she may be fostering intolerant beliefs as a means to relieve her mother of the responsibility for her mental ailments by placing the blame on someone else. This suggests an effort to preserve her mother's image as untouched, pure, and honourable, all traits commonly impressed upon Hindu women (Menon \& Bhasin, 1998; Virdee, 2013). This tendency to internalize parental trauma is observed in children with parents with acute stress disorder or posttraumatic stress disorder. The transmission of trauma from parent to child has been called 'secondary traumatic stress' by Figley (as cited in Pearrow and Cosgrove, 2009, p. 78). Children, and even grandchildren of victims (Cohn \& Morrison, 2018), may internalize their parent's trauma in an effort to feel closer to what may feel like an emotionally unavailable parent posttrauma (Salberg, 2015). Theories on the topic suggest that the child often feels disillusioned with the parent, and recognizes the trauma as a part of their relationship, in order to secure the bond between the two the child seeks to form a bond with their trauma as well (Gerson, 2009). This reflection of her mother's trauma may also be a result of over-disclosure or oversharing, where they are indiscriminately told the details of the parent's negative experience which the child absorbs and learns from. This may be the case with Neerja who recollected the struggles of her family's journey to India without her.

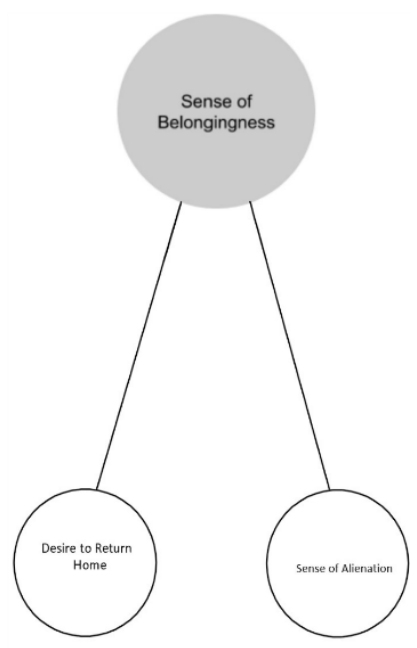




\section{Sense of Belongingness}

Displacement is associated with negative affect and a disorganized cultural identity (Taylor \& Usborne, 2010). The sense of belonging to a culture is arguably distinct from nationhood which may come with a more flexible criteria (Pilkington, 1998), whereas culture is defined by shared language, food, clothing, and so on. All the participants expressed some desire to return "home" where they remember all things as better; this may be representative of the identity associated with the memory which is more comfortable and familiar (Taylor \& Usborne, 2010). These sentiments are further explored as their desire to return home and their sense of alienation.

\section{Desire to return home}

All the participants expressed a deep desire to return home, except Ajit who was the only participant who witnessed his village get destroyed. For Neerja and Babita, the value of going back to Pakistan stands expressly in returning to their childhood home. As Neerja puts it when questioned about her desire to go back:

I: If you got the opportunity to go back, where would you go first?

$\mathrm{N}$ : (without missing a beat) My home.

I: You would go see your house.

$\mathrm{N}$ : Mhmm.

I: And the next place? (laughs)

$\mathrm{N}$ : The next place I would go...? Just go roam around and that's it.

I: In your community area and city?

$\mathrm{N}$ : Community area? Who would be in the community area? Just Muslims, no one else. Only Muslims, no

Hindus there anymore. Anyway, they must have—the dirt— the city's filthy now.

This passage suggests that to Neerja the image of her home that she carries with her may be based in the past, the way she remembers the house in her childhood. The house is an untouched haven that contains her life before she was displaced and the world around her formerhome encapsulates the world after the Partition; that is, to her the house remained the same while the world around it continued to change with time. Perhaps it is an intentional oversight in her perception of events to cope with displacement trauma. Nandrajog (2018) calls this "romanticizing the past" (p. 118) where the lost homeland is idealized as a lost paradise. However, in this case, it seems the participants wish to return to their homes, as opposed to wanting to return to the motherland. The discrepancy behind the motivation to return home may be the sources used to study the phenomena, since Nandrajog's (2018) observation is based on poetry and authors who wrote to engage a large audience, unlike the participants who were required to convey their personal experience. Alternatively, the focus on the home over the motherland may be gendered. Young girls were allowed limited exposure outside their homes (for example, Neerja who recalled being restricted to her home even before the conflict began) which may explain why their desire to return is confined around their homes, as well. The nostalgia is a commonly recurring theme throughout Partition literature, and evident in conversation between people. This may be an expression of alienation; the will to go home may represent the desire to go back to the people there, and the person they used to be.

\section{Sense of alienation}

Being displaced then settling into a new land makes it so the individual cannot belong to either side because, in this case, the Hindus and Sardars on the Indian side of the border were no more familiar to Babita, Neerja, and Ajit than the Muslims on the Pakistani side of the border (Nandrajog, 2018). Identity (and the subsequent loss of it) is displayed in how Babita refers to herself in her narrative when she recalls taking refuge in a neighbouring village:

B: So, (people in the village) knew, these are Gulatis from Lahore, they're Sardars. 
Babita's familial identity is closely tied to Lahore and acts as an identification for them in a social circle; it sets them apart in a group. Not only does it communicate to the third party that the Gulatis are from Lahore, it tells the person their culture, their communal values, and identifies them as a part of a larger community. Dominant groups in a cultural unit, such as Pakistani Hindus who held more power and owned more land than Pakistani Muslims (Bhasin \& Menon, 1998), are more disoriented and experience greater identity crises than do groups perceived as being less powerful (Pilkington, 1998). An example of this is when Babita's family relocated they were thrust into poverty and she felt inferior to the rest of her extended family that had recovered financially. Loss of property and resources also threatens one's identity within a social circle and sums in the need for a re-evaluation of identity to fit the current circumstances. Displacement and adapting to a new culture requires re-evaluating one's pre-existing identity and moulding it to fit the new culture (Taylor \& Usborne, 2010); this extends to the simplest of things such as food to more complex issues such as communication. This is exemplified by an interaction between Ajit and the interviewer where he struggles to communicate his point to the interviewer due to the dialectic difference:

A: ...After getting out, first, there was a kas where we hid. Then from there, we heard that we had to run, there was going to be an attack here as well.

I: Where did you hide, sorry?

A: It was--we call it kas.

I: Kas?

A: Kas.

I: Kas, meaning (chuckles)?

A: You know those deep places?

I: Deep place, okay okay.

A: (asks daughter in law to explain off camera)

A: So that is what it is. It was deep within the ground.

Language may closely be associated with national and ethnic identity. For instance, Russians forced to migrate identify their people based on language and land of origin (Pilkington, 1998). The difference in dialect identifies Ajit as a nonnative, as someone 'out of place'; the hyper awareness of cultural differences between the newly unified Indians resulted in condemnation at best (Nandrajog, 2018) and violence at its worst, such as the riots for the formation of the Sikh state of Khalistan (Hazarika, 1988). The themes observed in the analysis of the participants' narratives are similar to those in Nandrajog's analysis of literary works on the Partition. Low tolerance for other religions and a sense of alienation tie into Nandrajog's idea of loss of communal identity, alienation on either side of the border, and how refugees tend to rebuild their identity based on religion. Brave laughter may also be a signifier of the coping and the endurance of the human spirit as it recovers and makes sense of trauma. 


\section{Further Research}

Further studies on the topic may benefit from by studying different demographics, such as Muslim and South Indian populations. Moreover, a greater understanding of trauma in South Asian cultures is needed to better our understanding of trauma narratives and self-reported long term psychological impacts of stressful life events.

\section{Limitation}

There is a lack of Muslim and Pakistani representation in this study which does not reflect a spectrum of experiences observed in the trauma narratives of the participants. Virdee (2013) notes in her paper the strong bias toward Hindu and Indian participants in the study of the Partition. It is crucial that the unique experience of IndianMuslims and Pakistanis be studied as well to present well rounded data to highlight the similarities and differences in their recollection of 1947. The interviews were conducted by a third-party organization so no targeted data could be acquired from the participants, which restricts availability of data applicable to the topic of investigation.

\section{Conclusion}

This study shows the emotional experience of Partition survivors. Some of the prevalent themes observed in the narratives of Partition survivors are narrative tendencies, such as a focus on collective experience and brave laughter; mimicking of parental trauma; vividity of memories associated with emotionally charged events; desire to return home, and a sense of being alienated. The research allows for a greater insight into the psyche of the participants based on their lived experience of the Partition. Moreover, it offers an understanding of how adults may interpret their childhood trauma.

\section{References}

Brown, R., \& Kulik, J. (1977). Flashbulb memories. Cognition, 5(1), 7399. https://doi.org/10.1016/00100277(77)90018x

Grysman, A. (2012). Maintaining a positive sense of self: Distancing effects in autobiographical memory for negative events (PhD). The State University of New Jersey.

Menon, R., \& Bhasin, K. (1998). Borders \& Boundaries: Women in India’s Partition . Rutgers University Press.

Mushtaq, R. (2016). Posttraumatic stress disorder (Ptsd) in children of conflict region of kashmir (India): A review. JOURNAL OF CLINICAL AND DIAGNOSTIC RESEARCH. https://doi.org/10.7860/JCDR/2016/11766.7152

Nandrajog, H. (2018). Refugees of the partition of india: Trauma and strategies of recovery. In S. Jain \& A. Sarin, The Psychological Impact of the Partition of India (pp. 112-134). SAGE Publications, Inc.

https://doi.org/10.4135/9789353280703.n7

Neisser, U., \& Harsch, N. (1992). Phantom flashbulbs: False recollections of hearing the news about Challenger. In E. Winograd \& U. Neisser (Eds.), Affect and Accuracy in Recall (1st ed., pp. 9-31). Cambridge University Press. https://doi.org/10.1017/CBO9780511664069.003 
Pearrow, M., \& Cosgrove, L. (2009). The aftermath of combat related ptsd: Toward an understanding of transgenerational trauma. Communication Disorders Quarterly, 30(2), 77-82. https://doi.org/10.1177/1525740108328227

Pilkington, H. (2002). Migration, displacement and identity in postsoviet russia (1st ed.). Routledge. https://doi.org/10.4324/9780203444436

Salberg, J. (2015). The texture of traumatic attachment: Presence and ghostly absence in transgenerational transmission. The Psychoanalytic Quarterly, 84(1), 21-46. https://doi.org/10.1002/j.21674086.2015.00002.x

Shah, S., Byer, L., Appasani, R., \& Aggarwal, N. (2020). Impact of a community-based mental health awareness program on changing attitudes of the general population toward mental health in Gujarat, India - A study of 711 respondents. Industrial Psychiatry Journal, 29(1), 97. https://doi.org/10.4103/ipj.ipj_24_19

Smith, J., \& Osborn, M. (2003). Interpretative Phenomenological Analysis. In J. Smith, Qualitative Psychology: A Practical Guide to Research Methods. Sage. Retrieved 19 August 2020, from. Talarico, J. M., \& Rubin, D. C. (2007). Flashbulb memories are special after all; in phenomenology, not accuracy. Applied Cognitive Psychology, 21(5), 557-578. https://doi.org/10.1002/acp.1293

Talbot, I. (2009). Partition of india: The human dimension: introduction. Cultural and Social History, 6(4), 403-410. https://doi.org/10.2752/147800409X466254

Talbot, I. (2019). The 1947 Partition Violence: Characteristics and Interpretations. In R. Mohanram \& A. Raychaudhuri, Partitions and their Afterlives: Violence, Memories, Living. Rowman \&Littlefield International. Retrieved 19 August 2020, from. Taylor, D. M., \& Usborne, E. (2010). When I Know Who "We" Are, I Can Be "Me": The Primary Role of Cultural Identity Clarity for Psychological WellBeing. Transcultural Psychiatry, 47(1), 93-111. https://doi.org/10.1177/1363461510364569

Virdee, P. (2013). Remembering partition: Women, oral histories and the partition of 1947. Oral History (Colchester), 41(2), 4962.

Wardecker, B. M., Edelstein, R. S., Quas, J. A., Cordón, I. M., \& Goodman, G. S. (2017).

Emotion language in trauma narratives is associated with better psychological adjustment among survivors of childhood sexual abuse: Journal of Language and Social Psychology. https://doi.org/10.1177/0261927X17706940

Werner, E. E. (2012). Children and war: Risk, resilience, and recovery. Development and Psychopathology, 24(2), 553-558. https://doi.org/10.1017/S0954579412000156

Yusin, J. (2009). The silence of partition: Borders, trauma, and partition history. Social Semiotics, 19(4), 453-468. https://doi.org/10.1080/10350330903361141 